\title{
Autoantibodies Associated with Lupus Induced by Diverse Drugs Target a Similar Epitope in the (H2A-H2B)-DNA Complex
}

\author{
Robert L. Rubin, Susanne A. Bell, and Rufus W. Burlingame \\ W. M. Keck Autoimmune Disease Center, Department of Molecular and Experimental Medicine, \\ The Scripps Research Institute, La Jolla, California 92037
}

\begin{abstract}
IgG reactivity with the (H2A-H2B)-DNA complex, a subunit of the nucleosome, has been detected in many patients with lupus induced by procainamide and quinidine, but the similarity among the epitopes targeted by these antibodies in this heterogeneous patient group as well as the prevalence of this specificity in lupus induced by other drugs is unknown. Studies with histone-DNA complexes formed by sequential addition on a solid phase demonstrated that complexes containing single histones had negligible antigenicity, indicating that DNA stabilizes a protein epitope in the $\mathrm{H} 2 \mathrm{~A}-\mathrm{H} 2 \mathrm{~B}$ dimer or that the complete epitope is generated by a surface feature involving $\mathrm{H} 2 \mathrm{~A}$ H2B and DNA. $F\left(a^{\prime}\right)_{2}$ isolated from a patient with procainamide-induced lupus blocked $>90 \%$ of the anti- $[(\mathbf{H} 2 \mathrm{~A}-$ H2B)-DNA] reactivity in six of six sera from patients with lupus induced by procainamide, four of four quinidine-induced patients and in sera from patients with lupus induced by acebutolol, penicillamine, and isoniazid, but not methyldopa or autoantibodies to the component macromolecules. Fab fragments purified from the IgG of two quinidine-induced lupus patients and patients with isoniazid- and procainamide-induced lupus retained $39 \% \pm 8 \%$ of their original IgG reactivity compared to $34 \pm 28 \%$ of the original anti-tetanus toxoid activity of Fab fragments in two of the same sera and two normal sera. These results indicate that anti-[(H2A-H2B)-DNA] does not require divalent antigen-antibody complexes for stability, and that the complete epitope is created by the monomeric, trimolecular histone-DNA complex. We conclude that despite their pharmacologic and chemical heterogeneity, many lupus-inducing drugs elicit near identical autoantibodies. (J. Clin. Invest. 1992. 90:165-173.) Key words: drug-induced lupus • histones • penicillamine $\bullet$ methyldopa $\bullet$ acebutalol
\end{abstract}

\section{Introduction}

Drug-induced lupus (DIL) ${ }^{1}$ refers to a syndrome resembling the idiopathic autoimmune disease systemic lupus erythematosus (SLE) but is temporally related to long-term exposure to

Address reprint requests to Robert L. Rubin, Ph.D., BCR6, The Scripps Research Institute, 10666 North Torrey Pines Road, La Jolla, CA 92037.

Received for publication 22 October 1991 and in revised form 11 February 1992.

1. Abbreviations used in this paper: dDNA, denatured DNA; DIL, drug-induced lupus; mBSA, methylated BSA; nDNA, native DNA.

J. Clin. Invest.

(c) The American Society for Clinical Investigation, Inc. $0021-9738 / 92 / 07 / 0165 / 09 \$ 2.00$

Volume 90, July 1992, 165-173 pharmacologic agents $(1,2)$. A nonformalized but generally accepted criterion for DIL is remission of lupus-like symptoms after discontinuation of the implicated drug. Although it is unlikely that most forms of idiopathic SLE are causally related to exposure to drugs or unidentified environmental agents, understanding the mechanism underlying induction of autoimmunity by drugs may provide fundamental information on how autoimmune tolerance is broken in acquired systemic autoimmune diseases.

An interesting aspect of DIL, which is generally different from other systemic autoimmune diseases such as SLE, is that the autoantibody specificity is largely restricted to histone-containing antigens (3-6). Antihistone antibodies in DIL are responsible for the antinuclear antibodies seen in these sera (7), are generally not associated with other abnormal antibodies except antidenatured DNA (7-11), and gradually subside after discontinuation of the offending agent (12-14). Although antihistone antibodies can also be detected in asymptomatic patients treated with a variety of drugs, these antibodies are primarily of the IgM class and tend to react with all the individual histones relatively uniformly $(6,10,15,16)$. In contrast, symptomatic DIL is predominantly associated with IgG autoantibodies, and elevated reactivity with individual histones is commonly observed in lupus induced by procainamide ( $p$-amino$N$-[2-diethylaminoethyl]benzamide) (16-21) and hydralazine (1-hydrazinopthalazine) $(18,19,21,22)$.

The natural form of histones in vivo is the nucleosome, a well-defined structure consisting of a tetramer of histones $\mathrm{H} 3$ and $\mathrm{H} 4$ flanked on either side by a dimer of histones $\mathrm{H} 2 \mathrm{~A}$ and H2B; 168 basepairs of double-stranded DNA is wrapped twice around this histone octamer (23-25). $\mathrm{H} 1$ appears to associate with DNA where it exits the core particle and the $\sim 30$ basepairs of DNA linking the adjacent nucleosome (26). Although the structure of the histone octamer has been determined to high resolution (25), the precise positions of DNA and of $\mathrm{H} 1$ in the complete nucleosome are unknown. The folding of DNA around the octamer appears to require several sharp bends in the double helical B-form of DNA, but does not cause major disruption of base stacking or hydrogen bonding interactions (23).

The native $\mathrm{H} 2 \mathrm{~A}-\mathrm{H} 2 \mathrm{~B}$ dimer is highly antigenic for patients with procainamide-induced lupus since these sera show much less reactivity with the individual components of this complex, $\mathrm{H} 2 \mathrm{~A}$ and $\mathrm{H} 2 \mathrm{~B}$, or with detergent denatured $\mathrm{H} 2 \mathrm{~A}-\mathrm{H} 2 \mathrm{~B}(10,16$, $18,21)$. Binding of these antibodies is enhanced three- to fivefold if the H2A-H2B complex is associated with DNA, and this histone-DNA complex is especially antigenic for patients with quinidine(6'-methoxycinchonan-9-ol)-induced lupus (21). Anti-([H2A-H2B]-DNA) has also been reported in a patient with lupus induced by penicillamine (D-3-mercaptovaline) (14).

The present study examines the molecular requirements for antigen expression and the extent of antibody similarity in 
lupus induced by a diversity of drugs. The finding that autoantibodies induced by dissimilar drugs displayed the same specificity suggests the existence of a common pathway for induction of these antibodies, independent of the known pharmacology or chemical structure of the eliciting drug.

\section{Methods}

Patients. The penicillamine-induced lupus patient was a 50-yr-old female with rheumatoid arthritis treated with penicillamine for five years before a relatively sudden onset of symmetrical polyarthritis, fever, fatigue, and pleuritic chest pains with bilateral pleural effusions as described in detail (14); after discontinuation of penicillamine, symptoms gradually improved over the next several weeks and there has been no recurrence of her symptoms. The methyldopa (3-hydroxy- $\alpha$-methyltyrosine)-induced lupus patient had been treated with methyldopa for approximately one year before gradual onset of symmetrical polyarthritis, followed by a photosensitive rash, fatigue, exertional dyspnea, and weight loss as described (12); after discontinuation of methyldopa, his symptoms resolved and have not recurred during the following two years. The patient with isoniazid (isonicotinic acid hydrazide)-induced lupus was a 73-yr-old male undergoing antituberculosis therapy with isoniazid at $300 \mathrm{mg} / \mathrm{d}$. He developed a sudden onset of fever, malaise, erythematous and desquamative plaques on the malar region, nontender cervical lymphadenopathy, and pleuritis with bilateral pleural effusion; after discontinuation of isoniazid and initiation of prednisone $(20 \mathrm{mg} / \mathrm{d})$ his lupus-like symptoms gradually improved and have not recurred during the subsequent year (27). The acebutolol ( $N$-[3-acetyl4-[2-hydroxy-3-[(1-methylethyl)amino]propoxy]phenyl]-butanamide)induced lupus patient had been treated with this drug for two years before onset of arthralgia, pleuritis, and an array of constitutional symptoms; discontinuation of acebutolol was followed by symptom improvement over the next few months with no recurrence one year later. The patients with procainamide- and quinidine-induced lupus have been previously described $(10,21)$; remission of symptoms after discontinuation of therapy was a requisite criterion for diagnosis of drug-induced lupus in all cases. Anti-native DNA sera were derived from patients with SLE as previously described (28), and anti-H2B serum was obtained from a procainamide-treated patient who remained asymptomatic (7).

Antibody assays and antigen preparations. Human antibody binding to solid phase antigens was determined by ELISA as previously described (29). In general, sera and the IgG preparations were diluted 1:200, and bound antibody was detected with peroxidase-conjugated goat anti-human IgG or anti- $\lambda$-chain (Caltag Laboratories, South San Francisco, CA). The duration of incubation of the primary antibody and the secondary detecting reagents was $1.5-2 \mathrm{~h}$ and the OD of product development by peroxidase action was determined after 0.25 and 1 h. Antibody reactivity is expressed as OD after $1 \mathrm{~h}$; if the sample OD was $>2$ at $1 \mathrm{~h}$, antibody activity was calculated by extrapolation of the $\mathrm{OD}$ at $0.25 \mathrm{~h}$ as previously described (30).

Histones were salt-extracted from calf thymus (Pel-Freez Biologicals, Rogers, AR) and the H2A-H2B complex and the individual histones were isolated by column chromatography $(30,31)$. Calf thymus DNA was obtained from U.S. Biochemical Corp. (Cleveland, $\mathrm{OH}$ ) and subjected to proteinase $K$ and $S 1$ nuclease digestion followed by phenol extraction to obtain native DNA (nDNA) as described (29). Denatured DNA (dDNA) was produced by boiling nDNA for 10 min and quick cooling on ice. Tetanus toxoid was obtained from Lederle (Pearl River, $\mathrm{NY}$ ) and used at 1:300 dilution.

([H2A-H2B]-DNA)-complexes were produced in solution by mixing the H2A-H2B complex with nDNA in $2.0 \mathrm{M} \mathrm{NaCl}$ at a histone:DNA ratio of $0.75: 1$ followed by dialysis to low ionic strength buffer as previously described (30). Other forms of histone-DNA complexes were produced directly on the solid phase by sequential addition of either histone to nDNA or nDNA to histone in PBS. For the antinDNA assay and production of DNA + histone complexes on the plate, plates were first coated with methylated BSA $(\mathrm{mBSA})$ at $5 \mu \mathrm{g} / \mathrm{ml}$ before addition of nDNA at $10 \mu \mathrm{g} / \mathrm{ml}$. Plates were then postcoated with gelatin at $1 \mathrm{mg} / \mathrm{ml}$. For the plates coated with $\mathrm{nDNA}$ + histone, histone was added at $2.5 \mu \mathrm{g} / \mathrm{ml}$. Each coating step was performed for 8-18 h followed by rinsing with PBS between steps. The ELISA was performed the next day. For production of histone + DNA complexes on the plate, the plates were first coated with individual histones at $1 \mu \mathrm{g} / \mathrm{ml}$ or $\mathrm{H} 2 \mathrm{~A}-\mathrm{H} 2 \mathrm{~B}$ complexes at $2.5 \mu \mathrm{g} / \mathrm{ml}$ followed by postcoating and addition of $\mathrm{nDNA}$ at $10 \mu \mathrm{g} / \mathrm{ml}$. If histones or mBSA were not added before postcoating with gelatin, no solid phase nDNA bound to the plates. Similarly, if DNA was not added to mBSA-coated plates, no histone bound to the solid phase. These results indicate that macromolecular binding after postcoating occurred through protein-DNA interactions.

Immunoadsorption studies. Sera were incubated in a serial transfer protocol with wells coated with dDNA or dimer-DNA. Sera were diluted $1: 100$ to $1: 750$ and transferred to six replicate wells containing either dDNA, dimer-DNA, or gelatin. After incubation for $2 \mathrm{~h}$ with shaking, samples were transferred to and incubated with a fresh set of wells coated with the same antigen. This serial adsorption was repeated two more times. The next day the samples were assayed in triplicate for binding to dDNA and to dimer-DNA.

Antibody blocking experiments. The $\mathrm{F}\left(\mathrm{ab}^{\prime}\right)_{2}$ anti-[(H2A-H2B)DNA] from a patient with procainamide-induced lupus was prepared by treating $40 \mathrm{mg}$ of $50 \%$ saturated ammonium sulfate-purified IgG with $2 \mathrm{mg}$ of pepsin for $18 \mathrm{~h}$ at $37^{\circ} \mathrm{C}$ in $0.1 \mathrm{M}$ sodium acetate buffer $\mathrm{pH}$ 4.1. After dilution to the original serum volume and dialysis against PBS, the protein concentration was $2 \mathrm{mg} / \mathrm{ml}$. At $1: 50$ dilution this material produced $3.6 \mathrm{OD}$ reactivity with $(\mathrm{H} 2 \mathrm{~A}-\mathrm{H} 2 \mathrm{~B})-\mathrm{DNA}$ when detected with the anti-light chain reagent and $0.01 \mathrm{OD}$ when detected with the anti-IgG $(\mathrm{Fc})$. For blocking experiments, wells were coated with (H2A-H2B)-DNA and then incubated with the $\mathrm{F}\left(\mathrm{ab}^{\prime}\right)_{2}$ preparation at $1: 200$ dilution $(10 \mu \mathrm{g} / \mathrm{ml})$ for $1.5 \mathrm{~h}$. The test sera were diluted 1:200-1:80,000 in standard serum diluent (29) containing the $F\left(a^{\prime}\right)_{2}$ preparation at $1: 15$ dilution $(0.13 \mathrm{mg} / \mathrm{ml})$ and added to the wells. At the selected dilutions, unblocked samples produced an OD of $\sim 1$ on the (H2A-H2B)-DNA substrate. The control for each serum was with the $\mathrm{F}\left(\mathrm{ab}^{\prime}\right)_{2}$ preparation omitted in both steps. Samples were run in triplicate and ELISA performed as usual using an anti-IgG (Fc)-detecting reagent.

Fab preparation. Immunoglobulin from $0.5-1 \mathrm{ml}$ serum was isolated by precipitation with $50 \%$ saturated ammonium sulfate, dialyzed against $0.075 \mathrm{M}$ potassium phosphate buffer $\mathrm{pH} 8.0$, and applied to a 1.2-ml (bed volume) DEAE-Sephacel (Pharmacia Fine Chemicals, Piscataway, NJ) column in a 3-ml syringe. The fractions containing the flow-through, nonbound immunoglobulin (measured by $\mathrm{OD}_{280}$ ) were pooled and concentrated by precipitation with $50 \%$ saturated ammonium sulfate. The preparation was dissolved in the original volume of PBS and tested for immunoglobulin class-specific reactivity with (H2A-H2B)-DNA and other antigens; this material retained 53-96\% of the original IgG antibody reactivity, and no or negligible activity when measured with an anti-IgA or anti-IgM detecting reagent. The solution was adjusted to $2.5 \mathrm{mM}$ EDTA, $11 \mathrm{mM}$ cysteine, and mercuripapain (Worthington Biochemical Corp., Freehold, NJ) was added to half the preparation to a final concentration of $0.11 \mathrm{mg} / \mathrm{ml}$. After $20 \mathrm{~h}$ at $37^{\circ} \mathrm{C}$, iodoacetamide was added to the papain- and mock-digested solutions to a final concentration of $12 \mathrm{mM}$. The Fc fragment of the papain-digested material was removed by applying the sample to $200-\mu$ l bed volume Staphylococcus aureus protein A Sepharose CL-4B (Pharmacia) column contained in a 1-ml pipette, and the mock-digested sample was applied to a similar column of Sepharose CL-4B (without protein A). Column flow rate was $90 \mu \mathrm{l} / \mathrm{min}$. To adjust immunoglobulin from the papain- and mock-digested samples to the same Fab concentration, $35,000 \mathrm{cpm}$ human serum albumin radiolabeled with ${ }^{125} \mathrm{I}$ (DuPont Co., Wilmington, DE) by the chloramine T method (32) was added to both samples before Sepharose column chromatography. Peak fractions in the excluded volume were pooled and the concentrations of ${ }^{125} \mathrm{I}$ in the papain-digested and mock-digested samples were made identical. 
SDS gel electrophoresis. Samples from various stages of the Fab preparation were analyzed under "native" conditions by dilution into Laemmli sample buffer (33) modified by omission of $\beta$-mercaptoethanol and use of $0.05 \%$ SDS. Molecular weight markers (Bio-Rad Laboratories, Richmond, $\mathrm{CA}$ ) were boiled in standard sample buffer (containing $3 \%$ SDS and $5 \% \beta$-mercaptoethanol). Sample load was adjusted to give similar staining intensity for the $160-\mathrm{kD}$ IgG region and the 50-kD Fab + Fc region for the mock-digested and papain-digested samples, respectively. Electrophoresis was performed in a $45 \mathrm{~mm}$ long $\times 0.75 \mathrm{~mm}$ thick $10 \%$ polyacrylamide gel containing $0.1 \%$ SDS followed by silver staining (34).

\section{Results}

IgG autoantibodies were examined in patients with rare druginduced lupus, and a summary of these data is shown in Table I. At the time of symptom presentation, the predominant antibody activity in all four patients was detected when the (H2AH2B)-DNA complex was used as the test antigen. Analysis of serial serum samples demonstrated that anti-[(H2A-H2B)DNA] invariably decreased after discontinuation of the lupusinducing drug, consistent with the view that these antibodies were drug induced, although it took at least six months before significant loss in antibody activity was observed in the patients with penicillamine- and acebutolol-induced lupus. Anti[(H2A-H2B)-DNA] activity in the patient with methyldopa-induced lupus was not detected on the conventional preparation of this antigen but was observed on a complex formed de novo on the solid phase of the microtiter plate (see below). Little antibody binding to the component antigens, H2A-H2B or nDNA was generally observed, except for the patient with isoniazid-induced lupus who had substantial reactivity with $\mathrm{H} 2 \mathrm{~A}$ $\mathrm{H} 2 \mathrm{~B}$. The weak reactivity with nDNA complexed to mBSA in patients with acebutolol- and penicillamine-induced lupus was due to antibody binding to mBSA alone (data not shown). All sera had substantial antibody binding to dDNA, consistent with the common copresence of anti-dDNA antibodies in drug-induced autoimmunity $(11,16)$. However, when total histones were used as the test antigen, little, if any, antibody binding was observed. Total histones contain a relatively small amount of H2A and H2B in dimer form and histone-DNA complexes are absent because all traces of DNA were removed from the total histone preparation by DNase digestion and acid extraction. The lack of IgG reactivity with total histones highlights the restriction in antibody binding to the (H2A-H2B)DNA complex.

The copresence of anti-dimer-DNA with anti-dDNA raises the issue of whether these are separate antibody populations. Fig. 1 shows the capacity of dDNA and dimer-DNA immunosorbents to remove antibody activity in sera from three patients with DIL. Dimer-DNA adsorbed 50-90\% of anti-dimer-DNA activity with essentially no effect on anti-dDNA, indicating separate antibody populations. Solid phase dDNA removed 90-95\% of anti-dDNA, but anti-dimer-DNA was reduced from 10 to $40 \%$. This result could suggest that a portion of the anti-dimer-DNA activity in some sera may be due to binding of anti-dDNA to possible single-stranded regions in the DNA component of the dimer-DNA complex. However, this possibility is unlikely because the DNA used to make this complex was digested with S1 nuclease to remove single-stranded regions, and several human sera from asymptomatic procainamidetreated patients having high titer anti-dDNA had no reactivity with the dimer-DNA complex. However, we have found that $>70 \%$ of the antigenicity of dimer-DNA was inhibited after incubating dimer-DNA wells with $0.4 \mu \mathrm{g}$ of dDNA (or nDNA)

Table I. Antibodies in Rare Drug-induced Lupus

\begin{tabular}{|c|c|c|c|c|c|c|c|c|}
\hline \multirow[b]{2}{*}{ Patient } & \multirow[b]{2}{*}{ Date } & \multirow[b]{2}{*}{ Drug* } & \multirow[b]{2}{*}{$\begin{array}{l}\text { Clinical status } \\
\text { re DIL }\end{array}$} & \multicolumn{5}{|c|}{ IgG antibody activity (ELISA OD) } \\
\hline & & & & $\begin{array}{c}\text { (H2A-H2B)- } \\
\text { nDNA }\end{array}$ & H2A-H2B & $\begin{array}{l}\text { mBSA- } \\
\text { nDNA }\end{array}$ & $\begin{array}{c}\text { Total } \\
\text { histone }\end{array}$ & dDNA \\
\hline \multirow[t]{5}{*}{ DT } & & nicillam & & & & & & \\
\hline & $03 / 87$ & $\mathrm{D} / \mathrm{C}$ & Symptomatic & 4.12 & 0.00 & 0.55 & 0.11 & 1.99 \\
\hline & $05 / 88$ & $\mathrm{D} / \mathrm{C}$ & Asymptomatic & 4.25 & 0.00 & 0.46 & 0.08 & 1.64 \\
\hline & $08 / 88$ & $\mathrm{D} / \mathrm{C}$ & Asymptomatic & 2.79 & 0.03 & 0.33 & 0.16 & 1.89 \\
\hline & $03 / 89$ & $\mathrm{D} / \mathrm{C}$ & Asymptomatic & 1.18 & 0.00 & 0.02 & 0.00 & 0.83 \\
\hline \multirow[t]{5}{*}{ NR } & & cebutol & & & & & & \\
\hline & $08 / 88$ & $\mathrm{D} / \mathrm{C}$ & Symptomatic & 2.25 & 0.04 & 0.22 & 0.14 & 1.39 \\
\hline & $11 / 88$ & $\mathrm{D} / \mathrm{C}$ & Asymptomatic & 1.72 & 0.02 & 0.19 & 0.07 & 1.50 \\
\hline & $02 / 89$ & $\mathrm{D} / \mathrm{C}$ & Asymptomatic & 0.88 & 0.00 & 0.05 & 0.01 & 1.21 \\
\hline & $08 / 89$ & $\mathrm{D} / \mathrm{C}$ & Asymptomatic & 0.17 & 0.00 & 0.02 & 0.01 & 0.25 \\
\hline \multirow[t]{4}{*}{ FA } & & soniazid & & & & & & \\
\hline & $05 / 89$ & $\mathrm{D} / \mathrm{C}$ & Symptomatic & 1.29 & 0.47 & 0.02 & 0.21 & 0.95 \\
\hline & $06 / 89$ & $\mathrm{D} / \mathrm{C}$ & Asymptomatic & 0.85 & 0.30 & 0.01 & 0.09 & 0.27 \\
\hline & $02 / 90$ & $\mathrm{D} / \mathrm{C}$ & Asymptomatic & 0.04 & 0.11 & 0.25 & 0.44 & 0.11 \\
\hline \multirow[t]{5}{*}{$\mathrm{KK}$} & & ethyldor & & & & & & \\
\hline & $07 / 85$ & $\mathrm{D} / \mathrm{C}$ & Symptomatic & {$[1.84]^{\ddagger}$} & 0.06 & 0.02 & 0.06 & 0.48 \\
\hline & $11 / 85$ & $\mathrm{D} / \mathrm{C}$ & Asymptomatic & [1.09] & 0.01 & 0.02 & 0.00 & 1.67 \\
\hline & $01 / 86$ & $\mathrm{D} / \mathrm{C}$ & Asymptomatic & {$[1.11]$} & 0.00 & 0.01 & 0.02 & 1.25 \\
\hline & $12 / 86$ & $\mathrm{D} / \mathrm{C}$ & Asymptomatic & {$[0.50]$} & 0.00 & 0.00 & 0.00 & 0.18 \\
\hline
\end{tabular}

\footnotetext{
* Patients presented with lupus-like symptoms after long-term therapy with the indicated drug. Therapy was discontinued (D/C) on initial presenting date. ${ }^{\ddagger}$ The H2A-H2B dimer was added to solid phase nDNA rather than assaying with preformed (H2A-H2B)-nDNA complex.
} 


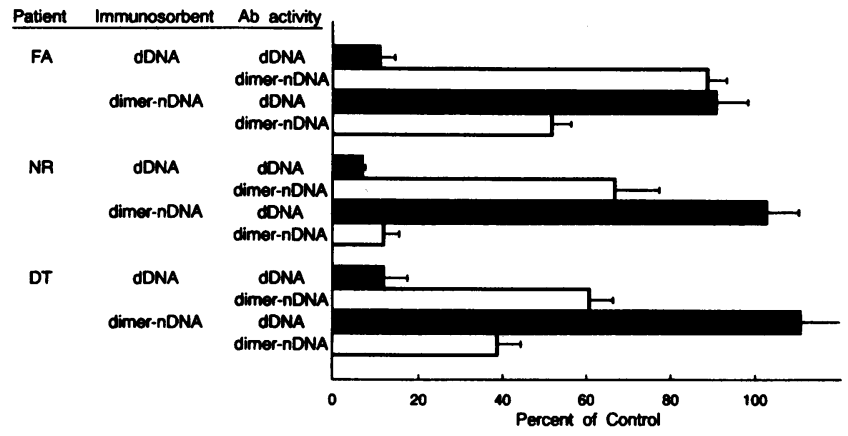

Figure 1. Antibody activity after immunoadsorption of sera. Sera from three patients were adsorbed with dDNA or dimer-DNA and tested for residual antibody activity to dDNA and dimer-DNA. Remaining antibody activity is expressed as percentage of that of the control sample which was adsorbed in parallel in a gelatin-coated well. For these control samples, anti-dDNA reactivity was 0.3 OD for patient FA, 0.8 OD for patient NR, and 0.2 OD for patient DT; antidimer-DNA for the same samples was 6.4 OD, 1.2 OD, and 3.3 OD, respectively. Error bars are SD and this is one of three similar experiments.

(data not shown). This effect is due to binding of soluble DNA to solid phase dimer-DNA since sera monospecific for antidDNA antibodies bound to dimer-DNA only after postincubation with dDNA (data not shown). Thus, the decrease in antidimer-DNA activity observed in two of the sera in Fig. 1 is likely due to the presence of soluble dDNA contaminating the samples after their serial immunoadsorption with dDNA. Taken together these results indicate that anti-dDNA and antidimer-DNA are separate populations of drug-induced antibodies.

The sera which reacted with preformed dimer-DNA in solid phase also bound to dimer-DNA in solution. In a direct competition study in which increasing amounts of soluble dimer-DNA were added to dimer-DNA coated wells before addition of the DIL sera, antibody binding to the solid phase was stoichiometrically decreased. The concentration of soluble dimer-DNA that produced $50 \%$ inhibition was $450 \pm 40 \mathrm{ng}$ for patient DT, $50 \pm 30 \mathrm{ng}$ for patient NR, and $960 \pm 85 \mathrm{ng}$ for patient FA, and $2.5 \mu \mathrm{g}$ soluble dimer-DNA inhibited $>75 \%$ of anti-dimer-DNA activity in all the sera. We previously determined that dimer-DNA wells contained $210 \mathrm{ng}$ of protein (30), so antibody binding to soluble dimer-DNA generally appears to be somewhat less efficient than binding to solid phase dimerDNA. However, these results indicate that the antigenicity of dimer-DNA is not substantially enhanced when bound to a solid phase.

Previous studies demonstrated that IgG antibody to the (H2A-H2B)-DNA complex was the predominant reactivity in patients with lupus induced by procainamide and by quinidine (21), but the importance of how this complex was formed and which histones are necessary for expression of antigenicity was not determined. To assess the similarity among the antibody specificities in patients in the present study and those with lupus induced by procainamide and quinidine, the relative antigenicities of the components of the (H2A-H2B)-DNA complex were compared. To maximize uniformity in orientation and amount of antigen on the ELISA plate, histone-DNA complexes were formed directly on the solid phase by sequential addition of either mBSA, nDNA and then histone, or histone and then nDNA. As shown in Fig. $2 A$, the four patients with rare drug-induced lupus showed a similar profile of reactivity with the test antigens, with maximum antigenicity when the H2A-H2B dimer was added to solid-phase DNA. The complex formed by addition of nDNA to the H2A-H2B dimer showed antigenicity which was similar to that of the preformed (H2AH2B)-DNA complex used in Table I (comparison not shown). The acebutolol-induced lupus serum had the same reactivity whether nDNA was added to the dimer or dimer was added to the nDNA, the penicillamine- and isoniazid-induced lupus sera displayed about one-half the activity when nDNA was added to the dimer and the methyldopa-induced lupus serum displayed no reactivity to the histone-DNA complex formed by addition of nDNA to H2A-H2B. The latter serum bound only when dimer-DNA was prepared by addition of $\mathrm{H} 2 \mathrm{~A}-\mathrm{H} 2 \mathrm{~B}$ to nDNA on the plate and did not react with preformed $(\mathrm{H} 2 \mathrm{~A}$ H2B)-DNA complex as indicated in Table I. The monomeric components of the (H2A-H2B)-DNA complex displayed little if any antigenicity with all the sera tested. Two of the sera bound individual histones $\mathrm{H} 2 \mathrm{~A}$ and $\mathrm{H} 2 \mathrm{~B}$, but antigenicity was not changed when these histones were bound to each other or to nDNA. These data indicate that the predominant epitope targeted by autoantibodies in rare drug-induced lupus is generated by a trimolecular complex requiring DNA, H2A, and $\mathrm{H} 2 \mathrm{~B}$.

Sera from 10 patients with procainamide-induced lupus and four patients with quinidine-induced lupus were also tested on various forms and components of the (H2A-H2B)DNA complex, and typical results are shown in Fig. 2, $B$ and $C$. The DNA + H2A-H2B preparation displayed predominant reactivity. Approximately one-half that level of activity was observed on H2A-H2B + DNA in all but two sera. One procainamide-induced lupus serum showed similar activity whether $\mathrm{H} 2 \mathrm{~A}-\mathrm{H} 2 \mathrm{~B}$ was added to $\mathrm{nDNA}$ or nDNA was added to H2A$\mathrm{H} 2 \mathrm{~B}$, and one quinidine-induced lupus serum had essentially no activity when nDNA was added to H2A-H2B. Many of the procainamide-induced lupus sera also reacted with $\mathrm{H} 2 \mathrm{~A}-\mathrm{H} 2 \mathrm{~B}$ directly on the plate, although the level of reactivity was usually three- to fourfold less than that of the (H2A-H2B)-DNA complex. As with the sera from patients with rare drug-induced lupus, the individual histones or individual histone-DNA complexes showed little if any antigenicity for most of the sera. The selective reactivity with DNA + H2A-H2B was not due to assay bias as shown in Fig. $2 \mathrm{D}$. Anti-nDNA from a patient with SLE displayed relatively uniform antibody binding to all the DNA-containing antigens, indicating that similar amounts of antibody-accessible DNA were present in all solid phase histone-DNA complexes. Reactivity of a serum from an asymptomatic patient treated with procainamide who developed IgG antibodies to H2B (7) showed similar reactivity with all the H2B-containing antigens except when nDNA was added to the H2A-H2B complex. Normal sera displayed negligible reactivity with all of the test antigens. Results with these control sera are consistent with previous studies (30), demonstrating that similar amounts of histone and histone-DNA complex are presented to antibody in random orientations on the solid phase.

Overall, the patients with rare drug-induced lupus and the patients with procainamide- and quinidine-induced lupus displayed remarkably similar profiles of reactivity with the tested antigens, suggesting that the same antibody specificity was associated with all these forms of drug-induced lupus. However, there are multiple epitopes on the (H2A-H2B)-DNA complex, 

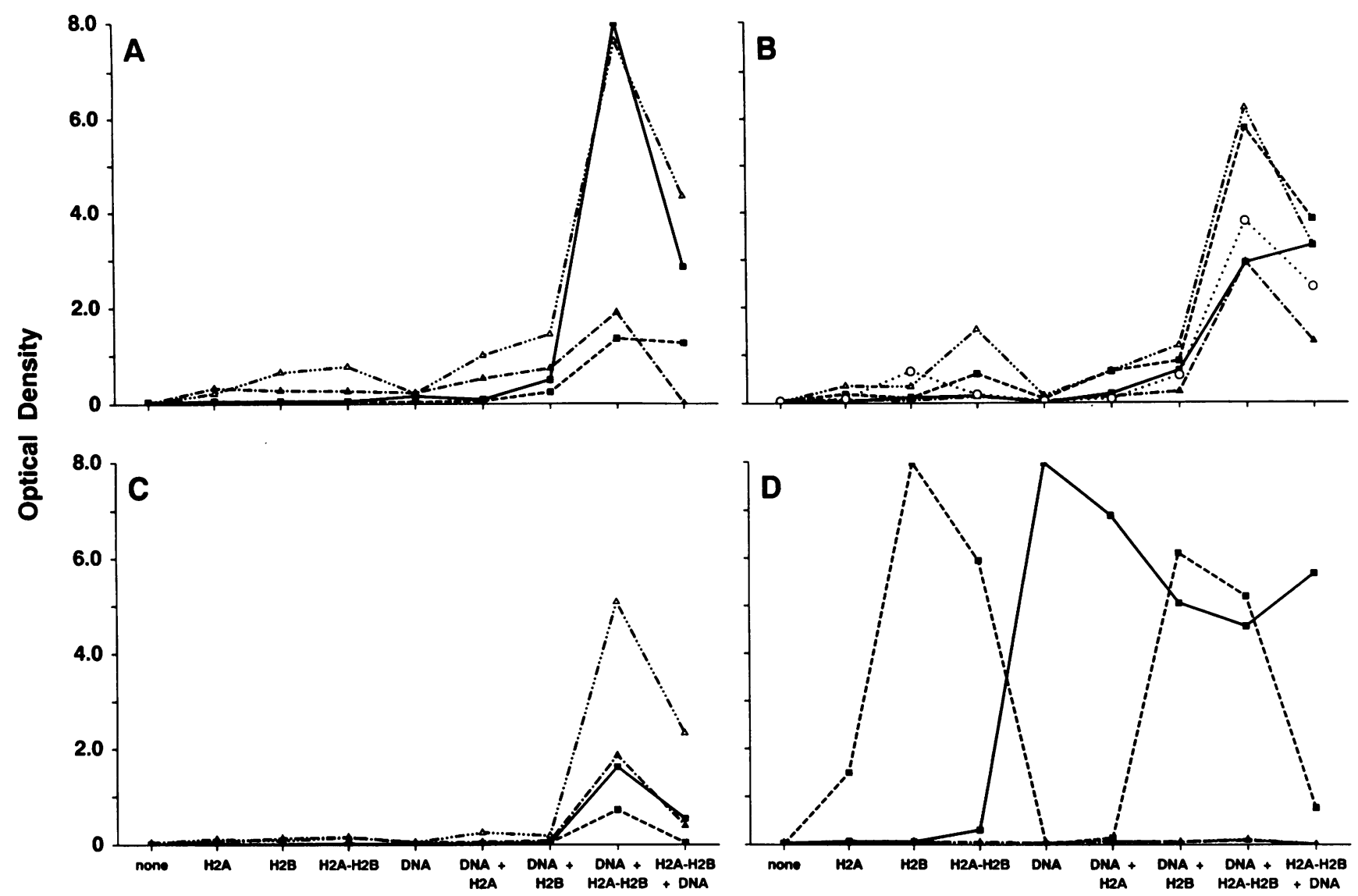

Figure 2. Antibody binding to components of the (H2A-H2B)-DNA complex in DIL. IgG antibody binding to histones, nDNA, and histonenDNA complexes formed directly on the solid phase was measured by ELISA. $(A)$ Patients with rare DIL: isoniazid $(\Delta-\cdots \Delta)$; penicillamine $(\square-\square)$; methyldopa $(\Delta-\cdot-\cdot \Delta)$; acebutolol (n-----). (B) Five patients with procainamide-induced lupus. (C) Four patients with quinidineinduced lupus. $(D)$ Control sera: SLE patient with anti-nDNA ( - - - ); asymptomatic procainamide-treated patient with anti-H2B ( $\square-----\square)$; a representative normal human serum $(\Lambda-\cdot-\cdot \Delta)$.

and sera may react with different epitopes. To explore this issue, the capacity of antibody from a procainamide-induced lupus patient to block IgG anti-[(H2A-H2B)-DNA] from other patients with drug-induced lupus was determined. An $\mathrm{F}\left(\mathrm{ab}^{\prime}\right)_{2}$ preparation was produced so that the blocking antibody would not be detected by the anti-IgG $(\mathrm{Fc})$ reagent used for monitoring antibody binding of the test sera. The $\mathrm{F}\left(\mathrm{ab}^{\prime}\right)_{2}$ preparation retained the full anti-[(H2A-H2B)-DNA] activity of its corresponding intact $\mathrm{IgG}$ when detected with an anti-light chain reagent but was undetectable when using the anti-Fc detecting reagent (data not shown). As shown in Fig. 3, this antibody blocked essentially all activity in all tested sera from patients with procainamide-induced lupus, including the serum from which it was derived. Similar blocking capacity of the $F\left(a^{\prime}\right)_{2}$ preparation was observed with the four patients with quinidine-induced lupus and three of the four patients with rare drug-induced lupus. Blocking was observed whether the antigen was (H2A-H2B)-DNA reconstituted in solution or if $\mathrm{H} 2 \mathrm{~A}$ H2B was added to nDNA-coated plates. The only exception was the patient with methyldopa-induced lupus in which only approximately one-third loss of anti-dimer-DNA activity was observed. This level of inhibition is within that observed in the control group consisting of four SLE sera with anti-nDNA antibodies and an asymptomatic procainamide-treated patient with anti-H2B. The lack of significant blocking of anti-nDNA or anti-H2B activities demonstrates that the $\mathrm{F}\left(\mathrm{ab}^{\prime}\right)_{2}$ antidimer-DNA did not cause wanton steric blocking of all antibodies reacting with this antigen. These results indicate that IgG anti-[(H2A-H2B)-DNA] antibodies from most of the drug-induced lupus patients recognize epitopes that are identical, overlapping, or in close proximity.

Although the H2A-H2B dimer is a small complex of $\sim 28$ $\mathrm{kD}$, a much larger, multimeric complex is likely to form when the dimer associates with DNA. Antibody binding in ELISA may require a multivalent dimer-DNA complex so that both arms of the IgG molecule need to bind for detection of the immune complex. In this way, enhanced binding to (H2AH2B)-DNA compared to DNA-free H2A-H2B would not be due to a neo-epitope formed by quaternary histone-DNA interactions, but by fortuitous spacing of the H2A-H2B dimer along the DNA fiber, facilitating bivalent binding of IgG. This possibility was tested by comparing the reactivity of monovalent Fab preparations of IgG with the respective intact IgG molecule. Because mere handling of IgG without inclusion of papain occasionally resulted in loss of binding, the activity of the Fab preparations was compared to mock-digested samples processed in parallel under identical conditions. As shown in Fig. 4, papain digestion converted essentially all the $160-\mathrm{kD}$ IgG molecular species to material migrating at $\sim 50 \mathrm{kD}$, the expected size of the Fab subunit. No binding of these Fab prepara- 


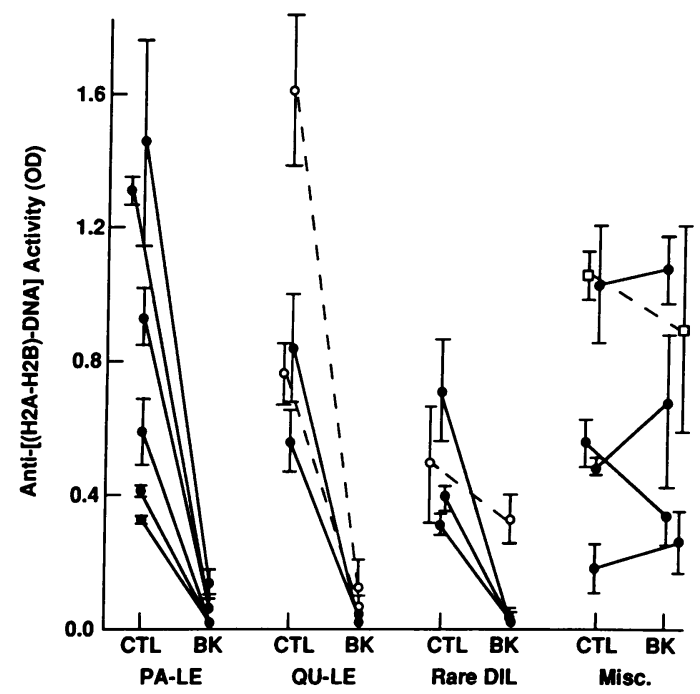

Figure 3. Effect of $\mathrm{F}\left(\mathrm{ab}^{\prime}\right)_{2}$-blocking antibody on reactivity of sera with anti-[(H2A-H2B)-DNA]. Sera from patients with procainamide-induced lupus (PA-LE), quinidine-induced lupus $(Q U-L E)$, rare DIL, or a miscellaneous group were diluted to produce IgG reactivity with (H2A-H2B)-DNA of $<2.0 \mathrm{OD}$ in the absence $(C T L)$ or presence of blocking $(B K) \mathrm{F}\left(\mathrm{ab}^{\prime}\right)_{2}$ anti-[(H2A-H2B)-DNA] antibody from a patient with PA-LE. Two of the QU-LE sera and the serum from the patient with methyldopa-induced lupus were tested on (H2A-H2B)DNA complexes formed by addition of H2A-H2B to nDNA on the plate (O-----O); all other sera were tested with preformed (H2AH2B)-nDNA adsorbed directly to the solid phase. The miscellaneous group consisted of four SLE sera with anti-nDNA antibodies and an asymptomatic procainamide-treated patient with anti-H2B (口----- $\square$ ). Variances are \pm 1 SD of a single representative experiment.

tions was observed when measured by an anti-Fc detecting reagent (Table II), indicating complete removal of the Fc fragment by papain digestion and protein A Sepharose chromatography. When antibody binding was measured with the anti-light chain detecting reagent, Fab fragments from two quinidine-, one procainamide-, and one isoniazid-induced lupus patient retained $28-49 \%$ of the dimer-DNA binding activity of the corresponding mock-digested preparations. The latter two patients also had significant IgG anti-tetanus toxoid activity, and binding of the corresponding Fab from these patients as well as from two normal sera with anti-tetanus toxoid antibody is also shown in Table II. Fab anti-tetanus toxoid had $9-74 \%$ of the binding activity of the mock-digested samples. These data show that loss in antibody binding upon conversion of the dimeric IgG to the monomeric Fab was similar for the anti-dimer-DNA and anti-tetanus toxoid antibodies (mean of $39 \%$ and $34 \%$, respectively, of the intact IgG activity), indicating bivalency enhanced the binding constants for anti-dimerDNA and antitetanus to similar extents. These results also demonstrate that anti-dimer-DNA activity did not display unusually stringent requirements for bivalent cross-linked antigen-antibody complexes for stability.

\section{Discussion}

The present study characterized and compared autoantibodies in patients with lupus induced by a variety of drugs. We have focused on antibody reactivity to the (H2A-H2B)-DNA com- plex and its components because this activity dominated the antibody response to histone-containing antigens in procainamide- and quinidine-induced lupus $(3,21)$. All sera displayed much lower or no binding to components of this complex, including individual histones with or without DNA. Excess antibody from a patient with procainamide-induced lupus blocked essentially all antibody reactivity to the (H2A-H2B)DNA complex from other patients with lupus induced by procainamide, quinidine, acebutolol, isoniazid, and penicillamine but did not block antibodies to DNA or to H2B. It appears, therefore, that antibodies in DIL have near identical epitope requirements, regardless of the drug that induced them.

Antibodies to individual histones have also been demonstrated in DIL, especially $\mathrm{H} 1$ and $\mathrm{H} 2 \mathrm{~B}$ in procainamide-induced lupus $(19,20), \mathrm{H} 1$ in methyldopa-induced lupus (12), and $\mathrm{H} 1$ and $\mathrm{H} 2 \mathrm{~B}$ in quinidine-induced lupus $(35,36)$. In fact, we previously reported IgG anti-individual histone antibodies in some of the patients in the present study, especially anti-H1 in procainamide- and quinidine-induced lupus (21). However, when compared to antibody to the (H2A-H2B)-DNA complex, anti-individual histone reactivity was relatively minor, and the pattern of reactivity with individual histones displayed wide patient-to-patient variability. In contrast, anti-[(H2A-H2B)DNA] was the one common serology that linked lupus induced by a diverse array of drugs. Certainly, the anti-[(H2A-H2B)DNA] specificity was not identical in all the sera used in the present study since there were subtle differences in the profiles of reactivity with the set of macromolecular components which comprise this complex. In fact, antibody from the methyldopainduced lupus patient bound to a unique and separate epitope on the dimer-DNA complex as shown by blocking experiments. However, considering that these are polyclonal antibodies from a heterogeneous patient population, the uniformly selective reactivity with a subunit of the nucleosome is remarkable.
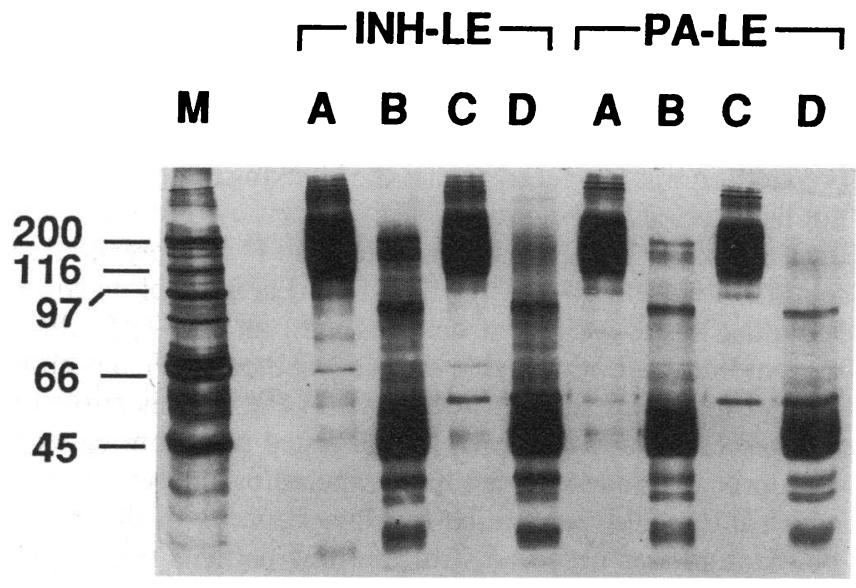

Figure 4. SDS-PAGE of Ig fractions during Fab preparation. The starting material was serum from a patient with isoniazid-induced lupus $(I N H-L E)$ or procainamide-induced lupus $(P A-L E)$. Samples applied to the gel were DEAE-Sephacel purified IgG after mock digestion $(A)$ or after papain digestion $(B)$, mock-digested sample after Sepharose chromatography $(C)$, and papain-digested sample after protein A Sepharose chromatography $(D)$. Molecular weight markers $(M)$ are shown in the left lane. This silver-stained gel was over-developed to maximize detection of intact IgG in the papain-digested samples. 


\begin{tabular}{|c|c|c|c|c|c|c|}
\hline \multirow[b]{2}{*}{ Sample } & \multirow[b]{2}{*}{ Antigen } & \multirow{2}{*}{$\begin{array}{l}\text { Detecting } \\
\text { antibody }\end{array}$} & \multicolumn{3}{|c|}{ Preparation binding activity $(\mathrm{OD} \pm \mathrm{SD})^{*}$} & \multirow{2}{*}{$\begin{array}{c}\text { Fab binding } \\
\text { (Percentage of mock) }\end{array}$} \\
\hline & & & $\lg G$ & Mock digest & Fab & \\
\hline & & & & & & $\%$ \\
\hline \multirow[t]{4}{*}{ INH-LE } & nDNA + dimer & $\alpha \mathrm{Fc}$ & $0.49 \pm 0.02$ & $0.64 \pm 0.02$ & 0.00 & 0 \\
\hline & & $\alpha \lambda$ & $0.38 \pm 0.01$ & $0.39 \pm 0.01$ & $0.19 \pm 0.02$ & 49 \\
\hline & Tetanus & $\alpha \mathrm{Fc}$ & $0.50 \pm 0.09$ & $0.65 \pm 0.10$ & 0.00 & 0 \\
\hline & & $\alpha \lambda$ & $0.13 \pm 0.03$ & $0.18 \pm 0.02$ & $0.05 \pm 0.02$ & 28 \\
\hline \multirow[t]{4}{*}{ PA-LE } & nDNA + dimer & $\alpha \mathrm{Fc}$ & $3.09 \pm 0.06$ & $1.06 \pm 0.14$ & 0.00 & 0 \\
\hline & & $\alpha \lambda$ & $1.23 \pm 0.07$ & $0.43 \pm 0.02$ & $0.16 \pm 0.03$ & 37 \\
\hline & Tetanus & $\alpha \mathrm{Fc}$ & $2.10 \pm 0.16$ & $2.07 \pm 0.13$ & 0.00 & 0 \\
\hline & & $\alpha \lambda$ & $0.55 \pm 0.02$ & $0.56 \pm 0.03$ & $0.05 \pm 0.01$ & 9 \\
\hline \multirow[t]{2}{*}{ QU-LE1 } & nDNA + dimer & $\alpha \mathrm{Fc}$ & $0.42 \pm 0.01$ & $0.48 \pm 0.03$ & 0.00 & 0 \\
\hline & & $\alpha \lambda$ & $0.71 \pm 0.02$ & $0.64 \pm 0.04$ & $0.19 \pm 0.01$ & 30 \\
\hline \multirow[t]{2}{*}{ QU-LE2 } & nDNA + dimer & $\alpha \mathrm{Fc}$ & $0.43 \pm 0.03$ & $0.56 \pm 0.01$ & 0.00 & 0 \\
\hline & & $\alpha \lambda$ & $0.41 \pm 0.02$ & $0.34 \pm 0.02$ & $0.13 \pm 0.01$ & 38 \\
\hline \multirow[t]{2}{*}{ NHS1 } & Tetanus & $\alpha \mathrm{Fc}$ & $1.91 \pm 0.06$ & $2.58 \pm 0.02$ & 0.00 & 0 \\
\hline & & $\alpha \lambda$ & $0.63 \pm 0.12$ & $0.77 \pm 0.05$ & $0.57 \pm 0.02$ & 74 \\
\hline \multirow[t]{2}{*}{ NHS2 } & Tetanus & $\alpha \mathrm{Fc}$ & $0.64 \pm 0.11$ & $0.80 \pm 0.01$ & 0.00 & 0 \\
\hline & & $\alpha \lambda$ & $0.84 \pm 0.11$ & $1.13 \pm 0.04$ & $0.28 \pm 0.03$ & 25 \\
\hline
\end{tabular}

* Reactivities of IgG and Fab from six normal sera were nil on nDNA + dimer. INH-LE, isoniazid-induced lupus; PA-LE, procainamide-induced lupus; QU-LE, quinidine-induced lupus; NHS, normal human serum.

Antibody binding to the preformed (H2A-H2B)-DNA complex was pronounced in all but one DIL serum. However, when dimer-DNA was formed directly on the solid phase by adding dimer to DNA-coated wells, antibody binding was enhanced two- to sevenfold and was the only form of the complex detected by the patient with methyldopa-induced lupus. This enhanced antigenicity was not due to larger amounts of DNA and/or dimer on the solid phase and was only partly related to orientation of the dimer to the solution side of the wells, since preformed dimer-DNA complex added to mBSA-coated wells had an antigenicity which was only $1.5 \pm 0.8(\mathrm{SD} n=10)$ times that of dimer-DNA bound directly to the plate, presumably in random orientation (data not shown). Binding of histones to DNA is very rapid in physiological solutions (37), and altered, possibly nonnative histone-DNA complexes may form under these fast binding conditions. The enhanced antigenicity of a nonnative (H2A-H2B)-DNA complex may provide insight into the form of the immunogen driving this autoantibody response.

Most of the sera had lower binding to the complex formed by adding DNA to solid phase dimer compared to (H2A-H2B)DNA complex formed in the reverse order. This result may be due to restricted mobility of plastic-bound dimer to engage in putative epitope-enhancing interaction with DNA. It is also possible that excess DNA may nonspecifically interfere with antibody access to the (H2A-H2B)-DNA complex as was observed when soluble DNA was added to plastic-bound dimerDNA complex.

The enhanced antigenicity of the DNA + H2A-H2B complex could be the result of nonrandom distribution of the $\mathrm{H} 2 \mathrm{~A}$ H2B complex on solid phase DNA, producing localized high concentrations of multiple epitopes and thereby facilitating stable interactions with both arms of the IgG molecule. This possibility was tested by comparing the binding of intact IgG with equimolar concentrations of the corresponding Fab. Although there was approximately two-thirds loss in anti-[(H2AH2B)-DNA] activity upon conversion of IgG to the Fab fragment, this decrease was not exceptionally large and similar to that observed for anti-tetanus toxoid antibody binding to solid phase, presumably randomly distributed tetanus toxoid. These results indicate that anti-[(H2A-H2B)-DNA $]$ antibodies do not have stringent requirements for divalent antigen-antibody complexes for stability. No binding of the Fab from procainamide- and isoniazid-induced lupus patients to the H2A-H2B complex was observed (data not shown), presumably because the affinity of DNA-free H2A-H2B for the monovalent autoantibodies was below the threshold level of detection. Since DNA enhanced the antigenicity of the H2A-H2B complex for both intact IgG as well as monovalent Fab, this phenomenon cannot be the result of a fortuitous, secondary effect of DNA that might promote bivalent immune-complex formation. Instead, DNA acts as a contributory (for some sera) or necessary component of the epitope, and the complete epitope consists of a monomeric, trimolecular histone-DNA complex.

Hypotheses to explain autoantibody production in DIL are often based on a drug-altered antigen concept (38). However, there is little evidence for a specific interaction between any lupus-inducing drug and histones, chromatin, or DNA at therapeutically relevant drug concentrations and physiological conditions. All the drugs in the present study except penicillamine have in common one or more benzene rings but their functional groups are dissimilar. The lipophilic character of the benzene ring may be important but certainly not sufficient for induction of autoimmunity since analogues such as $\mathrm{N}$-acetyl procainamide do not induce lupus or autoantibodies (39). The capacity of these drugs to react with macromolecules and cell receptors is widely different, reflecting the pharmacologic activities of their functional groups. Furthermore, there does not 
appear to be enough structural information in such diverse, small molecules to directly target any one macromolecular species such as histones, let alone the (H2A-H2B)-DNA subunit of the nucleosome. There is no known biochemical feature of the (H2A-H2B)-DNA complex that would confer upon it any special capacity to bind drugs. Therefore, the present findings demonstrating that dissimilar drugs induced near identical autoantibodies appear to make drug alteration of the antigen a largely untenable mechanism.

Chemically different drugs may have the same adverse reaction if they are transformed in vivo to products with similar reactive properties. Oxidative metabolism of procainamide to procainamide-hydroxylamine ( $p$-hydroxylamino- $N$-[2-diethylaminoethyl]-benzamide) by the hepatic microsomal monooxygenase system has been demonstrated in vitro $(40,41)$, and in vivo studies suggest that procainamide (42), hydralazine, and isoniazid (43) can undergo first-pass oxidative metabolism in the liver. Procainamide also undergoes extracellular transformation to procainamide-hydroxylamine by an enzymatic reaction with myeloperoxidase released from activated neutrophils (44). Unlike metabolism in the liver, neutrophil-mediated drug metabolism can generate even labile reactive metabolites directly in lymphoid compartments where an immunologic effect could take place. Procainamide-hydroxylamine is cytotoxic at micromolar concentrations (45), and cytotoxic products of hydralazine, quinidine, and isoniazid are also generated by activated neutrophils under pharmacologically relevant conditions (46). Cell death by redox cycling compounds such as procainamide-hydroxylamine $(45,47)$ appears to be associated with depletion of cellular energy stores and massive DNA strand breakage (45). This premature cell death may affect the intracellular pathway for chromatin catabolism during apoptosis (48), leading to abnormal forms of degraded chromatin which could be directly immunogenic. Alternatively, it has been proposed that low molecular weight forms of self-macromolecules may be normally involved in maintenance of nonneonatal immune tolerance to self (49). This view is consistent with the demonstration by Nossal and Karvelas (50) of the capacity of soluble antigen to inhibit a primary immune response and of Goodnow et al. (51) on the suppression of the immune response to lysozyme by in vivo secretion of this neoself antigen in mice transgenic for an inducible lysozyme gene. Subnucleosome particles consisting of the H2A-H2B dimer bound to DNA of 30-40 bp are released after extensive digestion of nuclei with micrococcal nuclease (26) or of 50-60 bp after shorter digestion times in the presence of $3 \mathrm{M}$ urea (52). If a similar process occurs in vivo, the resultant subnucleosome particles may suppress chromatin immunogenicity. It is possible that cytotoxic metabolites of lupus-inducing drugs affect chromatin breakdown to such putative tolerogens. The most exposed protein regions of the nucleosome core contain the H2A-H2B dimer (25); if immune tolerance to nDNA is intact, the immune response to chromatin may be limited to an epitope formed by this region and the adjacent DNA.

\section{Acknowledgments}

We thank Mark C. Totoritis, M.D., Division of Rheumatology, Scripps Clinic and Research Foundation, for access to the patient with acebutalol-induced lupus, Janice Arnott for expert technical help, and Caryl Kane and Julie Koehler for preparation of the manuscript.
This study was supported in part by grants AR-34358 from the National Institutes of Health and RR00833 from the U. S. Public Health Service. This is publication number 7059-MEM from The Scripps Research Institute.

\section{References}

1. Lee, S. L., and P. H. Chase. 1975. Drug-induced systemic lupus erythematosus: a critical review. Semin. Arthritis Rheum. 5:83-103.

2. Harmon, C. H., and J. P. Portanova. 1982. Drug-induced lupus: clinical and serological studies. Clin. Rheum. Dis. 8:121-135.

3. Fritzler, M. J., and E. M. Tan. 1978. Antibodies to histones in drug-induced and idiopathic lupus erythematosus. J. Clin. Invest. 62:560-567.

4. Tan, E. M. 1982. Autoantibodies to nuclear antigens. Their immunobiology and medicine. Adv. Immunol. 33:167-240.

5. Grossman, L., and P. Barland. 1981. Histone reactivity of drug-induced anti-nuclear antibodies. Arthritis Rheum. 24:927-930.

6. Epstein, A., M. Greenberg, S. Halpert, L. Kramer, and P. Barland. 1986. The clinical application of an ELISA technique for the detection of antihistone antibodies. J. Rheumatol. 13:304-307.

7. Rubin, R. L., G. Reimer, E. M. McNally, S. R. Nusinow, R. P. Searles, and E. M. Tan. 1986. Procainamide elicits a selective autoantibody immune response. Clin. Exp. Immunol. 63:58-67.

8. Klajman, A., R. Farkas, E. Gold, and S. Ben-Efraim. 1975. Procainamideinduced antibodies to nucleoprotein, denatured and native DNA in human subjects. Clin. Immunol. Immunopathol. 3:525-530.

9. Rubin, R. L. 1989. Autoimmune reactions induced by procainamide and hydralazine. In Autoimmunity and Toxicology: Immune Disregulation Induced by Drugs and Chemicals. M. Kammuller, M. Bloksma, and W. Seimen, editors. Elsevier Science Publishers B.V., Amsterdam. 119-150.

10. Totoritis, M. C., E. M. Tan, E. M. McNally, and R. L. Rubin. 1988. Association of antibody to histone complex H2A-H2B with symptomatic procainamide-induced lupus. N. Engl. J. Med. 318:1431-1436.

11. Weisbart, R. H., W. S. Yee, K. K. Colburn, S. H. Whang, M. K. Heng, and R. J. Boucek. 1986. Antiguanosine antibodies: a new marker for procainamideinduced systemic lupus erythematosus. Ann. Intern. Med. 104:310-313.

12. Nordstrom, D. M., S. G. West, and R. L. Rubin. 1989. Methyldopa-induced systemic lupus erythematosus. Arthritis Rheum. 32:205-208.

13. Rubin, R. L., S. R. Nusinow, A. D. Johnson, D. S. Rubenson, J. G. Curd, and E. M. Tan. 1986. Serological changes during induction of lupus-like disease by procainamide. Am. J. Med. 80:999-1002.

14. Enzenauer, R. J., S. G. West, and R. L. Rubin. 1990. D-penicillamine-induced systemic lupus erythematosus. Arthritis Rheum. 33:1582-1585.

15. Klajman, A., B. Kafri, T. Shohat, I. Drucker, T. Moalem, and A. Jaretzky. 1983. The prevalence of antibodies to histones induced by procainamide in old people, in cancer patients, and in rheumatoid-like diseases. Clin. Immunol. Immunopathol. 27:1-8.

16. Rubin, R. L., E. M. McNally, S. R. Nusinow, C. A. Robinson, and E. M. Tan. 1985. IgG antibodies to the histone complex H2A-H2B characterize procainamide-induced lupus. Clin. Immunol. Immunopathol. 36:49-59.

17. Portanova, J. P., R. L. Rubin, F. G. Joslin, V. D. Agnello, and E. M. Tan. 1982. Reactivity of anti-histone antibodies induced by procainamide and hydralazine. Clin. Immunol. Immunopathol. 25:67-79.

18. Portanova, J. P., R. E. Arndt, E. M. Tan, and B. L. Kotzin. 1987. Anti-histone antibodies in idiopathic and drug-induced lupus recognize distinct intrahistone regions. J. Immunol. 138:446-451.

19. Craft, J. E., J. A. Radding, M. W. Harding, R. M. Bernstein, and J. A. Hardin. 1987. Autoantigenic histone epitopes: a comparison between procainamide- and hydralazine-induced lupus. Arthritis Rheum. 30:689-694.

20. Gohill, J., and M. J. Fritzler. 1987. Antibodies in procainamide-induced and systemic lupus erythematosus bind the C-terminus of histone 1 (H1). Mol. Immunol. 24:275-285.

21. Burlingame, R. W., and R. L. Rubin. 1991. Drug-induced anti-histone autoantibodies display two patterns of reactivity with substructures of chromatin J. Clin. Invest. 88:680-690.

22. Hobbs, R. N., D. J. Lea, K. K. Phua, and P. M. Johnson. 1983. Binding of isolated rheumatoid factors to histone proteins and basic polycations. Ann. Rheum. Dis. 42:435-438.

23. Richmond, T. J., J. T. Finch, B. Rushton, D. Rhodes, and A. Klug. 1984. Structure of the nucleosome core particle at $7 \mathrm{~A}$ resolution. Nature (Lond.). 311:532-537.

24. Burlingame, R. W., W. E. Love, B.-C. Wang, R. Hamlin, N.-H. Xuong, and E. N. Moudrianakis. 1985. Crystallographic structure of the octameric histone core of the nucleosome at a resolution of $3.3 \mathrm{~A}$. Science (Wash. DC). 228:546-553. 
25. Arents, G., R. W. Burlingame, B.-C. Wang, W. E. Love, and E. N. Moudrianakis. 1991. The nucleosomal core histone octamer at $3.1 \AA$ resolution: a tripartite protein assembly and a left-handed superhelix. Proc. Natl. Acad. Sci. USA. 88:10148-10152.

26. Nelson, D. A., A. J. Mencke, S. A. Chambers, D. K. Oosterhof, and R. L. Rill. 1982. Subnucleosomes and their relationships to the arrangements of histone binding sites along nucleosome deoxyribonucleic acid. Biochemistry. 21:4350-4362.

27. Salazar-Paramo, M., R. L. Rubin, and I. Garcia-de la Torre. 1992. Isoniazid-induced systemic lupus erythematosus. Ann. Rheum. Dis. In press.

28. Rubin, R. L., F.-L. Tang, E. K. L. Chan, K. M. Pollard, G. Tsay, and E. M. Tan. 1986. IgG subclasses of autoantibodies in systemic lupus erythematosus, Sjogren's syndrome, and drug-induced autoimmunity. J. Immunol. 137:25282534.

29. Rubin, R. L. 1986. Enzyme-linked immunosorbent assay for anti-DNA and anti-histone antibodies. In Manual of Clinical Laboratory Immunology. N. R. Rose, H. Friedman, and J. L. Fahey, editors. American Society for Microbiology, Washington. 744-749.

30. Burlingame, R. W., and R. L. Rubin. 1990. Subnucleosome structures as substrates in enzyme-linked immunosorbent assays. J. Immunol. Methods. 134:187-199.

31. Bohm, E. L., W. N. Strickland, M. Strickland, B. H. Theraits, D. R. Von der Westhuizen, and C. Von Holt. 1973. Purification of the five main calf thymus histone fractions by gel exclusion chromatography. FEBS (Fed. Eur. Biochem. Soc.) Lett. 34:217-221.

32. Hunter, W. M. 1973. Radioimmunoassay. In Handbook of Experimental Immunology. D. M. Weir, editor. Blackwell Scientific Publications, Oxford 17.1-17.36.

33. Laemmli, U. K. 1970. Cleavage of structural proteins during the assembly of the head of bacteriophage T4. Nature (Lond.). 227:680-685.

34. Wray, W., T. Boulikas, V. P. Wray, and R. Hancock. 1981. Silver staining of proteins in polyacrylamide gels. Anal. Biochem. 118:197-203.

35. West, S. G., M. McMahon, and J. P. Portanova. 1984. Quinidine-induced lupus erythematosus. Ann. Intern. Med. 100:840-842.

36. Cohen, M. G., S. Kevat, M. V. Prowse, and M. J. Ahern. 1988. Two distinct quinidine induced rheumatic syndromes. Ann. Intern. Med. 108:369371 .

37. Daban, J.-R., and C. R. Cantor. 1982. Structural and kinetic study of the self-assembly of nucleosome core particles. J. Mol. Biol. 156:749-769.

38. Parker, C. W. 1981. Hapten immunology and allergic reactions in humans. Arthritis Rheum. 24:1024-1036.

39. Lahita, R., J. Kluger, D. E. Drayer, D. Koffler, and M. M. Reidenberg.
1979. Antibodies to nuclear antigens in patients treated with procainamide or acetylprocainamide. $N$. Engl. J. Med. 301:1382-1385.

40. Uetrecht, J. P., B. J. Sweetman, R. L. Woosley, and J. A. Oates. 1984. Metabolism of procainamide to a hydroxylamine by rat and human hepatic microsomes. Drug Metab. Dispos. 12:77-81.

41. Budinsky, R. A., S. M. Roberts, E. A. Coats, L. Adams, and E. V. Hess. 1987. The formation of procainamide hydroxylamine by rat and human liver microsomes. Drug Metab. Dispos. 15:37-43.

42. Wheeler, J. F., L. E. Adams, A.-B. Mongey, S. M. Roberts, W. R. Heineman, and E. V. Hess. 1991. Determination of metabolically derived nitroprocainamide in the urine of procainamide-dosed humans and rats by liquid chromatography with electrochemical detection. Drug Metab. Dispos. 19:691-695.

43. Hein, D. W., and W. W. Weber. 1989. Metabolism of procainamide, hydralazine, and isoniazid in relation to autoimmune(-like) reactions. In Autoimmunity and Toxicology. M. E. Kammueller, N. Bloksma, and W. Seinen, editors Elsevier Science Publishers B.V., Amsterdam. 239-265.

44. Rubin, R. L., and J. T. Curnutte. 1989. Metabolism of procainamide to the cytotoxic hydroxylamine by neutrophils activated in vitro. J. Clin. Invest. 83:1336-1343.

45. Rubin, R. L., J. P. Uetrecht, and J. E. Jones. 1987. Cytotoxicity of oxidative metabolites of procainamide. J. Pharmacol. Exp. Ther. 242:833-841.

46. Rubin, R. L. 1991. Transformation of lupus-induced drugs to reactive products by activated neutrophils. Arthritis Rheum. 34:S146.(Abstr.)

47. Roberts, S. M., L. E. Adams, R. Donovan-Brand, R. Budinsky, N. P. Skoulis, H. Zimmer, and E. V. Hess. 1989. Procainamide hydroxylamine lymphocyte toxicity-1. Evidence for participation by hemoglobin. Int. J. Immunopharmacol. 11:419-427.

48. Rechsteiner, M. 1991. Ubiquitin-mediated pathways for intracellular proteolysis. Annu. Rev. Cell Biol. 3:1-30.

49. Dintzis, H. M., and R. Z. Dintzis. 1988. A molecular basis for immune regulation: the immunon hypothesis. In Theoretical Immunology. Part One, SFI Studies in the Sciences of Complexity. A. S. Perelson, editor. Addison-Wesley Publishing Co., Reading, MA. p. 83.

50. Nossal, G. J. V., and M. Karvelas. 1990. Soluble antigen abrogates the appearance of anti-protein IgG1-forming cell precursors during primary immunization. Proc. Natl. Acad. Sci. USA. 87:1615-1619.

51. Goodnow, C. C., J. Crosbie, H. Jorgensen, R. A. Brink, and A. Basten. 1989. Induction of self-tolerance in mature peripheral B lymphocytes. Nature (Lond.). 342:385-391.

52. Mencke, A. J., and R. L. Rill. 1982. Circular dichroism and thermal denaturation studies of subnucleosomes and their relationships to nucleosome structure. Biochemistry. 21:4362-4370. 